\title{
CAQDAS and Ethics: starting point for something bigger
}

\author{
CAQDAS e Ética: ponto de partida para algo maior \\ CAQDAS y Ética: punto de partida para algo más grande
}

António Pedro Costa ${ }^{1}$

${ }^{1}$ Universidade de Aveiro, Centro de Investigação Didática e Tecnologia na Formação de Formadores, Departamento de Educação e Psicologia, Aveiro, Portugal. e-mail: apcosta@ua.pt

How to cite this article:

Costa AP. CAQDAS and Ethics: starting point for something bigger [editorial]. Rev Esc Enferm USP. 2020;54:e03598. doi: https:// doi.org/10.1590/S1980-220X2020ed0103598

The use of specific tools, such as for the analysis of qualitative data, is something that we could almost qualify as unavoidable. The researcher may have realized that it is relevant to inform his/her reader about which tool s/he used to analyse this type of data, in some cases, even though s/he did not use any of them. In this context, due to different factors, researchers sometimes lose the notion of "how to be". We thus entered the field of ethics in the use of technologies. According to Ingleby ${ }^{(1)}$, "ethics concern right and wrong, good and bad" (p. 51) and "ethical considerations will arise from the very nature of the particular research being pursued at the time: situation determines behaviour" (p. 61).

The same author presents a set of steps. One is related to respect for protocol. In fact, the researcher must ensure that all those involved, whether they are informants, groups, entities or relevant authorities, are consulted and informed about the study that is being conducted and that everyone has obtained the inevitable consent and agreement to proceed, respecting eventual refusals. However, a study ${ }^{(2)}$ introduce a concept calling 'MyTerms,' "in which prospective participants tailor the terms and conditions of informed consent to their personalized preferences for receiving information, including research results" (p. 1081).

On the other hand, there is a whole other set of participants that has to be involved in the equation, ensuring that the goals and objectives of the research project are enriched by broad, possibly disparate, but equally important, views of the former. Given that we are not always lucky enough to get everyone to participate in a committed way, we must negotiate and ensure that their participation, responsibilities and aspirations are taken into account.

All progress must be kept open, transparent and receptive to criticism and suggestions that allow the natural "blindness" of those who get too caught up in a study to be clarified by other perspectives and points of view, giving it substance and enriching it. After all, since research work is eminently inquisitive in nature, peer questioning should never be overlooked.

It is here that the need to progressively refine the various stages of progress of the study report, depending not only on its purpose but also on the public or the audience to which it is directed. An oral presentation, necessarily a summary of a work that is current and that has been read with particular attention. For the defense, before a panel of experts in a public exam to obtain a degree, it will not be done in the same tone or with the same degree of depth as if it is a context of public disclosure of the same work (for example, at a conference, a speciality journal, a poster, a public science text). All these contexts, among others, always have ethical implications, be they academic and scientific, as well as confidentiality and data protection. This does not mean, however, that the researcher is "tied up" concerning his/her right to make the work public - indeed, that is his/her deontological duty. The tools that try to measure the quality of the analyses performed (COREQ, QRE Tool) question their users about the number of researchers involved in the coding process. In cases where it is not possible to involve another researcher in the coding process, involvement in validation procedures employing some techniques (i.e., Delphi technique) can reduce the bias. All principles underlying any study involving other persons should form a solid basis of a mutual and informed agreement before its commencement. 
Moreover, this agreement must remain alive and faithful, with regular checks by those involved that such principles are maintained throughout the research process, including the decision to make their knowledge public. When we are using software, it is essential to read the terms and conditions of the tool I choose to analyze the data. Otherwise, that allowed removing coresearchers, experts that invited to validate specific part of categories, remove account or project, among others.

The observations made above are transversal to any research work and should not be taken as negligible. There are, however, other aspects of ethics that arise from the use of technologies that also deserve reflection. Examples of this are the ways in which collaborative research ${ }^{(3-4)}$ mediated by technologies that involve online sharing and simultaneous work of data that are intended to be reliable, and which depend on the degree of suitability of the team members. There is no point in sharing sensitive data that is not respected in the same way by everyone with respect to their confidentiality and degree of sensitivity, whether they involve personal aspects (of the researchers themselves and the participants), institutional (funding entities, hosting institutions and, eventually, of data collection settings, among others), or even scientific that may generate capital gains - such as data which, because of their potential commercial nature, will require, by such nature, the signature of confidentiality terms, and which should not be disrespected.

In the case of specific qualitative data analysis software it would be possible to list a set of principles that would begin with the organization and importing of the data, then their interpretative and descriptive codification, followed by questioning the data, up to the exporting of results and their written "exhibition". These principles could set the boundaries or define an ethics in the use of software, referring to any research activity that tackles what is right or wrong, good or bad, moral or immoral ${ }^{(5)}$ as far as data analysis supported by software is concerned.

\section{REFERENCES}

1. Ingleby E. Research methods in education. Prof Dev Educ. 2012;38(3):507-9. https://doi.org/10.1080/19415257 .2011 .643130

2. Nebeker C, Leow AD, Moore RC. From return of information to return of value: ethical considerations when sharing individual-level research data. J Alzheimers Dis. 2019;71(4):1081-8. doi: 10.3233/JAD-190589

3. Costa AP, Souza DN, Souza FN. Trabalho colaborativo na investigação qualitativa através das tecnologias. In: Souza DN, Costa AP, Souza FN, editors. Investigação qualitativa: inovação, dilemas e desafios. Aveiro, Portugual: Oliveira de Azeméis/Ludomedia; 2016. p. 105-27.

4. Costa EP, Costa AP. O trabalho colaborativo apoiado pelas tecnologias: o exemplo da investigação qualitativa. Rev EDaPECI. 2017;17(2):61-9. doi: https://doi.org/10.29276/redapeci.2017.17.26660.61-69

5. Stahl BC, Eden G, Jirotka M, Coeckelbergh M. From computer ethics to responsible research and innovation in ICT: the transition of reference discourses informing ethics-related research in information systems. Inf Manage. 2014;51(6):810-8. doi: https://doi.org/10.1016/j.im.2014.01.001 